\title{
Moderate hypocapnia for intracranial pressure control after traumatic brain injury: a common practice requiring further investigations
}

\author{
Thomas Geeraerts ${ }^{1,2^{*}}$ (1)
}

(c) 2021 Springer-Verlag GmbH Germany, part of Springer Nature

Hypocapnia and hyperventilation are often considered as secondary insults to the brain. After traumatic brain injury (TBI), hypocapnia induces vasoconstriction, increases cerebral oxygen extraction fraction, and decreases cerebral blood flow and volume and intracranial pressure (ICP) [1-3]. Increases in brain extracellular glutamate and lactate concentrations in tissue adjacent to cerebral contusions or underlying subdural hematomas have been observed after 30 min of hyperventilation $\left(\mathrm{PaCO}_{2}\right.$ around $\left.25 \mathrm{mmHg}\right)$, particularly in the first 24-36 h after injury, suggesting deleterious metabolic effects of profound hypocapnia in vulnerable regions [4]. Thirty years ago, a good quality randomized controlled trial, even if performed in a relatively small groups, comparing the effects of severe and prolonged hypocapnia $(25 \pm 2 \mathrm{mmHg})$ to normocapnia $(35 \pm 2 \mathrm{mmHg})$ for a period of 5 days after severe TBI, found a worse neurological outcome in the hyperventilation group at 3 and 6 months, but not at 12 months [5]. The effect of moderate hypocapnia remains, however, controversial as the balance between potential negative metabolic effects and better ICP control may be considered. Some guidelines suggest that moderate hypocapnia could be used as a second-tier therapy [6]; others suggest that hyperventilation can be recommended only as a temporizing measure for the reduction of elevated ICP [7], and that

*Correspondence: geeraerts.t@chu-toulouse.fr

${ }^{1}$ Department of Anesthesiology and Critical Care, University Hospital of Toulouse, University Toulouse 3-Paul Sabatier, Toulouse, France

Full author information is available at the end of the article hyperventilation should be avoided during the first $24 \mathrm{~h}$ after injury $[7,8]$.

The study from Citerio et al. [9] offers a very interesting window of the current practices regarding $\mathrm{PaCO}_{2}$ management in the first week after severe TBI in Europe. Based on a large, prospective, observational cohort, the Center-TBI initiative, the authors were able to include 1100 TBI patients under mechanical ventilation, $65 \%$ of them with severe TBI (initial Glasgow Coma Scale 8 or less). Patients with $(n=751)$ or without $(n=349)$ ICP monitoring were studied and the outcome was measured at 6 months using the extended Glasgow Outcome Scale. The main findings can be summarized as follows:

- Moderate hyperventilation was widely used in European trauma centers, probably as a treatment of raised ICP, as suggested by the fact that $\mathrm{PaCO}_{2}$ levels were lower in patients with ICP monitoring and even lower in patients with raised ICP.

- An important heterogeneity across centers was highlighted, without important effects of the nation, suggesting that some centers, independently of the country, used hypocapnia and hyperventilation as a routine treatment for raised ICP.

- No strong effects of hypocapnia occurrence in the first week on 6-month mortality and neurological outcome were observed

This photograph of the current practices of expert European centers raises some important questions. First, the interplay between carbon dioxide and cerebral perfusion pressure must be considered. Meng and 
Gelb propose that during hypocapnia, and in relation with cerebral vasoconstriction, the autoregulation plateau descends and the lower limit remains unchanged, without significant effect on plateau length [10]. Some important clinical implications have been suggested to reduce brain ischemic risk in case of hyperventilation/ hypocapnia use: avoid hypotension, consider higher cerebral perfusion pressure, and avoid other drugs with cerebral vasoconstrictive effects. Studying the effects of the complex interaction between cerebral perfusion pressure, autoregulation, and carbon dioxide on neurological outcome is probably of interest in an integrated physiological approach.

Secondly, hypocapnia and hyperventilation are often treated as binary, not continuous criteria (yes or no, one or two measures per day). Using continuous end tidal carbon dioxide readings could offer the possibility to estimate the real effect of the total "dose" of hypocapnia in the first week and better explore its burden on brain physiology and outcome.

Furthermore, as most of the secondary insults to the brain, hypocapnia may have more negative effects if it occurs in the first hours after the trauma as suggested by Marion et al., showing a more important metabolic effect of hypocapnia in the first 24-36 h after injury [4], and by the fact that prehospital hypocapnia has been shown to be associated with increased mortality [11] and decrease in good outcome after severe TBI [12].

Finally, TBI patients and traumatic brain lesions are highly heterogenous. The effectiveness of different strategies to reduce ICP is highly dependent on the type of lesion. For example, TBI patients with large contusion, altered cerebral autoregulation, and poor vessel reactivity to pressure and carbon dioxide may not benefit from perfusion pressure increase, moderate hyperventilation, hypothermia, and/or metabolic suppression for ICP control. Good quality dataset, like the Center-TBI initiative can offer, could be used to test these crossed hypotheses in large cohorts and to reconsider the role of moderate hypocapnia after severe TBI.

\section{Author details}

${ }^{1}$ Department of Anesthesiology and Critical Care, University Hospital of Toulouse, University Toulouse 3-Paul Sabatier, Toulouse, France. ${ }^{2}$ Toulouse Neuroimaging Center, INSERM, University Toulouse 3-Paul Sabatier, Toulouse, France.

\section{Declarations}

Conflicts of interest

The author has no conflict of interest to declare.

\section{Publisher's Note}

Springer Nature remains neutral with regard to jurisdictional claims in published maps and institutional affiliations.

Received: 16 July 2021 Accepted: 18 July 2021

Published online: 14 August 2021

\section{References}

1. Laffey JG, Kavanagh BP (2002) Hypocapnia. N Engl J Med 347:43-53. https://doi.org/10.1056/NEJMra012457

2. Coles JP, Fryer TD, Coleman MR et al (2007) Hyperventilation following head injury: effect on ischemic burden and cerebral oxidative metabolism. Crit Care Med 35:568-578. https://doi.org/10.1097/01.CCM.00002 54066.37187 .88

3. Diringer MN, Videen TO, Yundt K et al (2002) Regional cerebrovascular and metabolic effects of hyperventilation after severe traumatic brain injury. J Neurosurg 96:103-108. https://doi.org/10.3171/jns.2002.96.1. 0103

4. Marion DW, Puccio A, Wisniewski SR et al (2002) Effect of hyperventilation on extracellular concentrations of glutamate, lactate, pyruvate, and local cerebral blood flow in patients with severe traumatic brain injury. Crit Care Med 30:2619-2625. https://doi.org/10.1097/00003246-20021 2000-00001

5. Muizelaar JP, Marmarou A, Ward JD et al (1991) Adverse effects of prolonged hyperventilation in patients with severe head injury: a randomized clinical trial. J Neurosurg 75:731-739. https://doi.org/10.3171/jns. 1991.75.5.0731

6. Hawryluk GWJ, Aguilera S, Buki A et al (2019) A management algorithm for patients with intracranial pressure monitoring: the Seattle international severe traumatic brain injury consensus conference (SIBICC). Intensive Care Med 45:1783-1794. https://doi.org/10.1007/ s00134-019-05805-9

7. Carney N, Totten AM, O'Reilly C et al (2017) Guidelines for the management of severe traumatic brain injury, fourth edition. Neurosurgery 80:6-15. https://doi.org/10.1227/NEU.0000000000001432

8. Geeraerts T, Velly L, Abdennour L et al (2018) Management of severe traumatic brain injury (first 24 hours). Anaesth Crit Care Pain Med 37:171-186. https://doi.org/10.1016/j.accpm.2017.12.001

9. Citerio G, Robba C, Rebora P et al (2021) Management of arterial partial pressure of carbon dioxide in the first week after traumatic brain injury: results from the CENTER TBI study. Intensive Care Med. https://doi.org/10. 1007/s00134-021-06470-7

10. Meng L, Gelb AW (2015) Regulation of cerebral autoregulation by carbon dioxide. Anesthesiology 122:196-205. https://doi.org/10.1097/ALN.00000 00000000506

11. Dumont TM, Visioni AJ, Rughani Al et al (2010) Inappropriate prehospital ventilation in severe traumatic brain injury increases in-hospital mortality. J Neurotrauma 27:1233-1241. https://doi.org/10.1089/neu.2009.1216

12. Davis DP, Hoyt DB, Ochs M et al (2003) The effect of paramedic rapid sequence intubation on outcome in patients with severe traumatic brain injury. J Trauma. https://doi.org/10.1097/01.TA.0000053396.02126.CD 